\title{
A statistical feature of anomalous seismic activity prior to large shallow earthquakes in Japan revealed by the pattern informatics method
}

\author{
M. Kawamura ${ }^{1}$, Y.-H. Wu ${ }^{2}$, T. Kudo ${ }^{3}$, and C.-c. Chen $^{2}$ \\ ${ }^{1}$ Department of Geosciences, National Taiwan University, Taipei 10617, Taiwan \\ ${ }^{2}$ Department of Earth Sciences and Graduate Institute of Geophysics, National Central University, Jhongli, Taoyuan 32001, \\ Taiwan \\ ${ }^{3}$ General Education Division, College of Engineering, Chubu University, Kasugai, Aichi 487-0027, Japan \\ Correspondence to: M. Kawamura (mkawamu@ntu.edu.tw)
}

Received: 7 February 2013 - Published in Nat. Hazards Earth Syst. Sci. Discuss.: 26 March 2013

Revised: 22 October 2013 - Accepted: 26 February 2014 - Published: 14 April 2014

\begin{abstract}
To reveal the preparatory processes of large inland earthquakes, we systematically applied the pattern informatics (PI) method to earthquake data of Japan. We focused on 12 large earthquakes with magnitudes greater than $M=6.4$ (based on the magnitude scale of the Japan Meteorological Agency) that occurred at depths shallower than $30 \mathrm{~km}$ between 2000 and 2010. We examined the relationship between the spatiotemporal locations of these large shallow earthquakes and the locations of PI hotspots, which correspond to grid cells of anomalous seismic activity during a designated time span. Based on a statistical test conducted using Molchan's error diagram, we investigated whether precursory anomalous seismic activity occurred in association with these large earthquakes and, if so, studied the characteristic time spans of such activity. Our results indicate that Japanese inland earthquakes with $M \geq 6.4$ are typically preceded by anomalous seismic activity in timescales of 8-10 years.
\end{abstract}

\section{Introduction}

Japan has been struck by many large $(M \geq 6.4)$ inland earthquakes, including the 2000 western Tottori Prefecture earthquake, the 2004 mid-Niigata Prefecture earthquake, the 2005 west of Fukuoka Prefecture earthquake, the 2007 Noto Hanto earthquake, the 2007 Niigata-ken Chuetsu-oki earthquake, and the 2008 Iwate-Miyagi Nairiku earthquake. Most of these earthquakes occurred along faults that had not been considered active prior to their occurrence (Imanishi et al., 2006). Therefore, a more detailed survey of poorly mapped active faults is required to ensure accurate modeling of the mechanisms underlying the occurrence of large inland earthquakes and to calculate strong motions at various sites including plain regions. Moreover, further and more detailed investigation of the statistical features of large inland earthquakes is also required. In particular, to ensure a comprehensive understanding of the preparatory processes of large inland earthquakes, the systematic investigation of the statistical features of seismic activity prior to large inland earthquakes is essential.

Seismic activity is sensitive to stress in the crust (Dieterich, 1994; Dieterich et al., 2000; Toda et al., 2002). Therefore, investigation of temporal changes in seismic activity is essential to understand temporal variations in such stress and may, in turn, provide information regarding the possibility of occurrence of future large earthquakes. Temporal changes in seismic activity before large earthquakes have been reported for various regions including Alaska (Bufe et al., 1994; Kisslinger and Kindel, 1994), California (Bowman et al., 1998; Bowman and King, 2001; Bufe and Varnes, 1993; Jaume and Sykes, 1999; Papazachos et al., 2005; Resenberg and Matthews, 1988; Sobolev, 2003; Stuart, 1991; Sykes and Jaume, 1990), central Asia (particularly the IndiaEurasia collision zone; Zheng et al., 1995), China (Wei et al., 1978; Yu et al., 2011), Greece (Karakaisis et al., 2002; Papazachos et al., 2005), Italy (Console et al., 2000), Japan 
(Huang et al., 2001; Mogi, 1969; Nagao et al., 2011; Ogata, 2004, 2005; Resenberg and Matthews, 1988; Papazachos et al., 2010; Katsumata, 2011a, 2011b), Russia (Borovik et al., 1971), Taiwan (Chen, 2003; Chen et al., 2005, 2006; Chen and $\mathrm{Wu}, 2006$; $\mathrm{Wu}$ and Chiao, 2006; $\mathrm{Wu}$ and Chen, 2007; Wu et al., 2008a, 2008b, 2011), and Turkey (Öztürk and Bayrak, 2012).

The results of these previous studies imply that anomalous seismic activity is associated with the preparatory processes of large earthquakes near their epicenters and in surrounding regions over various timescales. However, few studies to date have systematically investigated temporal changes in seismic activity prior to large earthquakes or the statistical characteristics of such activity. A systematic examination of precursory seismic activity is necessary to provide a comprehensive understanding of the preparatory processes of large earthquakes and may provide insight into the mechanisms underlying these processes. To address this, we systematically investigated precursory changes in seismic activity for large earthquakes in inland Japan using the pattern informatics (PI) method, which has retrospectively succeeded in identifying anomalous seismic activity prior to large earthquakes (Chen et al., 2005, 2006; Holliday et al., 2005, 2006; Rundle et al., 2002, 2003; Tiampo et al., 2002; Wu et al., 2008a, b, 2011). In Sect. 2, we introduce the analysis procedures used to derive a spatiotemporal PI map using the PI method, which identifies PI hotspots exhibiting anomalous change in seismic activity. The PI maps illustrate the relationships between the spatiotemporal locations of areas of anomalous seismic activity and those of large inland earthquakes; these maps are presented along with Molchan's error diagrams in Sect. 3 and are discussed in Sect. 4.

\section{Data and methodology}

We used the earthquake catalog maintained by the Japan Meteorological Agency (JMA). JMA initiated a new data processing operation in October 1997, aiming to unify the earthquake catalogs maintained by different organizations. Furthermore, JMA also began to relocate past seismic events using different velocity models and initiated changes in the methods used to calculate the JMA's magnitude $(M)$ in 2003. Accordingly, inhomogeneity has been induced in the earthquake catalog; this inhomogeneity can be attributed primarily to differences between seismic networks, improvements in observation instruments, and changes made to data processing methods (Habermann, 1987; Nanjo et al., 2011; Resenberg and Matthews, 1988). Investigation of the spatial and temporal homogeneity of the JMA earthquake catalog is important for evaluating temporal changes in seismic activity. Therefore, to examine the homogeneity of the catalog, we mapped the minimum magnitude of completeness $\left(M_{\mathrm{c}}\right)$ with grid cell intervals of 80 and $100 \mathrm{~km}$ at depths of $0-30 \mathrm{~km}$ from January 1980 onward using the method of Wiemer and
Wyss (2000); to calculate $M_{\mathrm{c}}$ for each grid cell, we used the surrounding 200 earthquakes. Application of this method produced $M_{\mathrm{c}}<3.5$, which is consistent with the results of Huang et al. (2001) and Nanjo et al. (2010). Thus, we first used events with $M \geq 3.5$ (i.e., a cutoff magnitude of 3.5) for application of the PI method. We also conducted analyses using events with $M \geq 4.0$ and 4.5 to examine the effects of different cutoff magnitudes on the statistical features of the spatiotemporal PI maps obtained.

The PI method was originally developed based on the concept of pattern dynamics (Rundle et al., 2000). Stress can be regarded as a space-time state variable in a system of true deterministic dynamics, and is a fundamental measure that must be monitored to allow identification of its temporal change in advance of large earthquakes. However, direct observation of stress change is difficult because earthquakes occur below the surface of the earth. To address this, new instruments have been developed to allow the observation of seismic activity with higher precision and accuracy; seismic activity is considered to be a type of stress sensor (Ma et al., 2005; Stein, 1999; Toda et al., 2002), and is determined based on seismographic information. Here, we selected seismic activity as a space-time state variable of pattern dynamics to investigate change in an earthquake system.

We applied the PI method to earthquake data for Japan (the rectangular region in Fig. 1) as follows and as illustrated in the flowchart in Fig. 2. (1) The target region is set and divided into grid cells with specific intervals $(80 \mathrm{~km} \times 80 \mathrm{~km}$ and $100 \mathrm{~km} \times 100 \mathrm{~km}$ for cutoff magnitudes of 3.5 and 4.0 or 4.5 , respectively). (2) The seismic intensity change $\Delta I_{\mathrm{i}}$ $\left(t_{b}, t_{1}, t_{2}\right)$ is calculated for the $i$ th grid cell for a target time period from $t_{1}$ to $t_{2}$ (defined as the change interval), where $t_{1}=t_{2}-t_{c}\left(t_{c}=4,6,8,10,12\right.$, and $14 \times 365$ days $)$ and $t_{2}=1$ October 1997 to 28 February 2011. This calculated change is used to obtain an index (PI value) likely representing the probability of earthquake occurrence during the prediction period from $t_{2}$ to $t_{3}$, where $t_{3}-t_{2}=t_{2}-t_{1}=t_{c}$. Seismic intensity $I_{\mathrm{i}}\left(t_{b}, t\right)$ is defined as the number of earthquakes per day within a square area that includes the $i$ th grid cell, averaged over the time period between a reference time $t_{b}$ (where $t_{0}<t_{b}<t_{1}$ and $t_{0}$ is 1 January 1980) and $t$. The lengths of the sides of the square are varied depending on the cutoff magnitude, forming squares of $240 \mathrm{~km} \times 240 \mathrm{~km}$ and $300 \mathrm{~km} \times 300 \mathrm{~km}$ for cutoff magnitudes of 3.5 and 4.0 or 4.5 , respectively. To obtain seismic intensity change, seismic intensities $I_{\mathrm{i}}\left(t_{b}, t_{1}\right)$ and $I_{\mathrm{i}}\left(t_{b}, t_{2}\right)$ for the $i$ th grid cell are calculated for the corresponding time periods (i.e., $t_{b}$ to $t_{1}$ and $t_{b}$ to $t_{2}$, respectively). Then, seismic intensity change is calculated as follows: $\Delta I_{\mathrm{i}}\left(t_{b}, t_{1}, t_{2}\right)=I_{\mathrm{i}}\left(t_{b}, t_{2}\right)-I_{\mathrm{i}}\left(t_{b}, t_{1}\right)$. (3) Step (2) is repeated to obtain seismic intensity changes for all grid cells. (4) To extract coherent trends in seismic intensity change during the period from $t_{1}$ to $t_{2}$, seismic intensities $I_{\mathrm{i}}\left(t_{b}, t_{1}\right)$ and $I_{\mathrm{i}}\left(t_{b}, t_{2}\right)$ are calculated by shifting $t_{b}$ from $t_{0}$ to $t_{1}$; then, seismic intensity change $\Delta I_{\mathrm{i}}\left(t_{b}, t_{1}, t_{2}\right)$ is normalized temporally by subtracting its temporal mean 
(a)

(b)

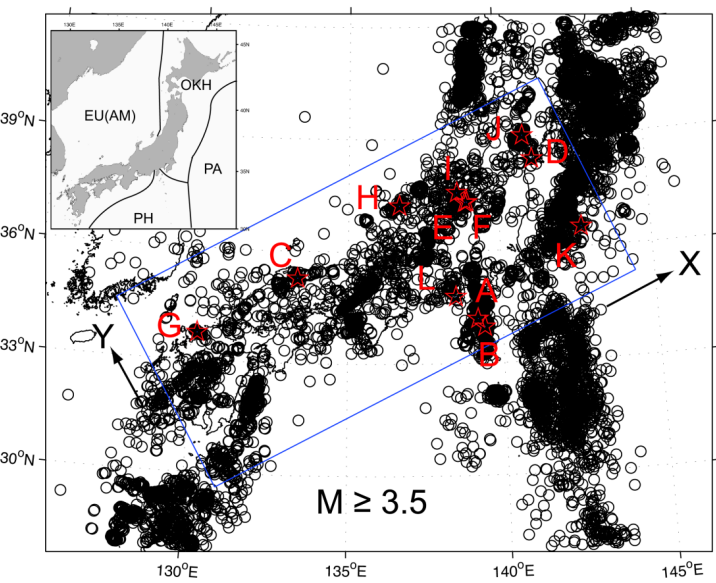

(c)
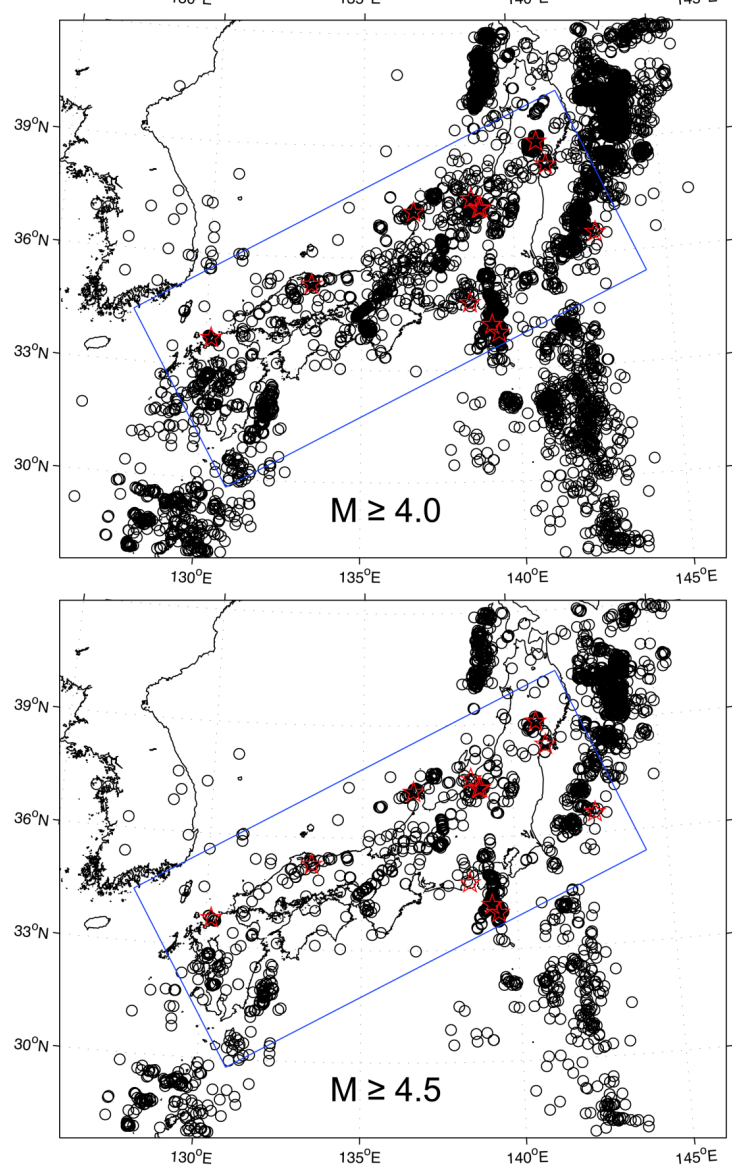

Fig. 1. Maps showing epicenters within rectangular regions used for PI analysis for threshold magnitudes of (a) 3.5, (b) 4.0, and (c) 4.5. The red stars with labels (A)-(L), which correspond to earthquake indices in Table 1, indicate the locations of large earthquakes with magnitudes larger than $M=6.4$. The black circles denote locations of earthquakes with magnitudes larger than a threshold magnitude as shown in respective panels. The $X$ and $Y$ axes of the rectangular region in each panel correspond to the east-northeastward and its perpendicular (north-northwestward) directions, respectively. The inset of (a) shows a map view of the tectonic setting around the Japanese islands; PA: Pacific Plate, PH: Philippine Sea plate, EU (AM): Eurasian Plate (Amurian Plate), OKH: Okhotsk Plate. and dividing by its temporal standard deviation. Additionally, $\Delta I_{\mathrm{i}}\left(t_{b}, t_{1}, t_{2}\right)$ is normalized spatially to highlight unusual seismic intensity changes. The value of $\Delta I_{\mathrm{i}}\left(t_{b}, t_{1}, t_{2}\right)$ varies depending on the grid cells in which $t_{b}$ is fixed; therefore, it can be normalized spatially by subtracting its spatial mean and then dividing by its spatial standard deviation for each value of $t_{b}$. The spatiotemporally normalized seismic intensity change can then be obtained, denoted as $\Delta \hat{I}_{\mathrm{i}}\left(t_{b}, t_{1}, t_{2}\right)$. (5) Most of the effects of random fluctuation in seismic intensity change and background seismic intensity change are eliminated by normalization, such that the preseismic change can be represented by the spatiotemporally normalized seismic intensity change $\Delta \hat{I}_{\mathrm{i}}\left(t_{b}, t_{1}, t_{2}\right)$. The preseismic change that occurs during preparatory processes can be seismic quiescence, seismic activation, or even both; therefore, $\Delta \hat{I}_{\mathrm{i}}\left(t_{b}, t_{1}, t_{2}\right)$ may be negative or positive. To incorporate all preseismic change and reduce the fluctuation of random noise, we take the absolute value of the spatiotemporally normalized seismic intensity $\left|\Delta \hat{I}_{\mathrm{i}}\left(t_{b}, t_{1}, t_{2}\right)\right|$ and average this absolute value over all values of $t_{b}$ to obtain $\left|\Delta \hat{I}_{\mathrm{i}}\left(t_{b}, t_{1}, t_{2}\right)\right|$. (6) Then, the probability of earthquake occurrence $P_{\mathrm{i}}\left(t_{1}, t_{2}\right)$ is defined as $\left.\overline{\left\langle\Delta \hat{I}_{\mathrm{i}}\left(t_{b}, t_{1}, t_{2}\right)\right.}\right|^{2}$ and the average probability as the mean $\mu_{\mathrm{p}}$ of $P_{\mathrm{i}}\left(t_{1}, t_{2}\right)$. The probability of earthquake occurrence relative to the background mean, $\Delta P_{\mathrm{i}}\left(t_{1}, t_{2}\right) \equiv{\overline{\mid \Delta \hat{I}_{i}\left(t_{b}, t_{1}, t_{2}\right)}}^{2}-\mu_{\mathrm{p}}$, is further divided by the spatial maximum $\left(\Delta P_{\max }\right)$; thus the obtained $\Delta P_{\mathrm{i}} / \Delta P_{\max }$ is defined as PI value. The common logarithm of the PI value is color coded and plotted on a PI map (not shown in the present study). (7) The end of change interval $t_{2}$ is moved forward ( $t_{1}$ and $t_{3}$ are changed accordingly, by the same time interval) and steps (2) to (6) are conducted again. (8) Finally, the common logarithm of $\Delta P_{\mathrm{i}} / \Delta P_{\max }$ (PI value) for each grid cell for each change interval is color coded and plotted on a spatiotemporal PI map (Figs. 3-5).

\section{Results}

Figures 3-5 illustrate the spatiotemporal PI maps for cutoff magnitudes of 3.5, 4.0, and 4.5; grid cells with large changes in seismic activity (i.e., PI hotspots) for different change intervals $(4,6,8,10,12$, and 14 years) are highlighted. Colored grid cells with the common logarithm of PI values greater than -0.4 (i.e., between -0.4 and 0 ) represent spatiotemporal locations with large changes in seismic activity; such changes likely represent seismic quiescence or seismic activation and are related to high probabilities of earthquake occurrences during the prediction periods, the lengths of which are equal to those of the change intervals (Fig. 2). The grid cells colored red represent the greatest changes in seismic activity, which typically correspond to the highest probabilities of earthquake occurrence in the prediction period. Conversely, the grid cells colored deep blue represent 

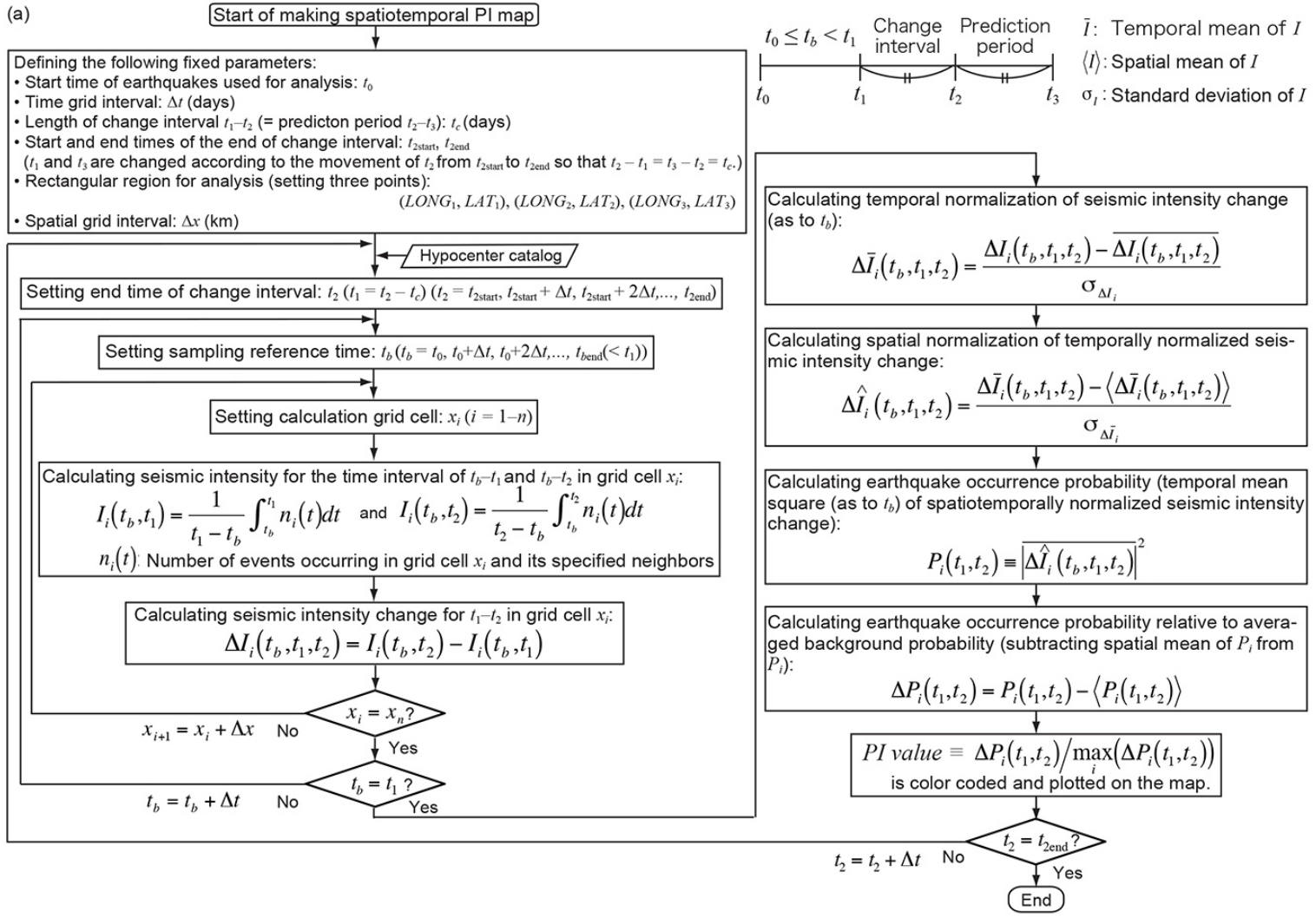

(b) $\quad$ PI maps for respective change intervals $\left(t_{1}-t_{2}\right)$
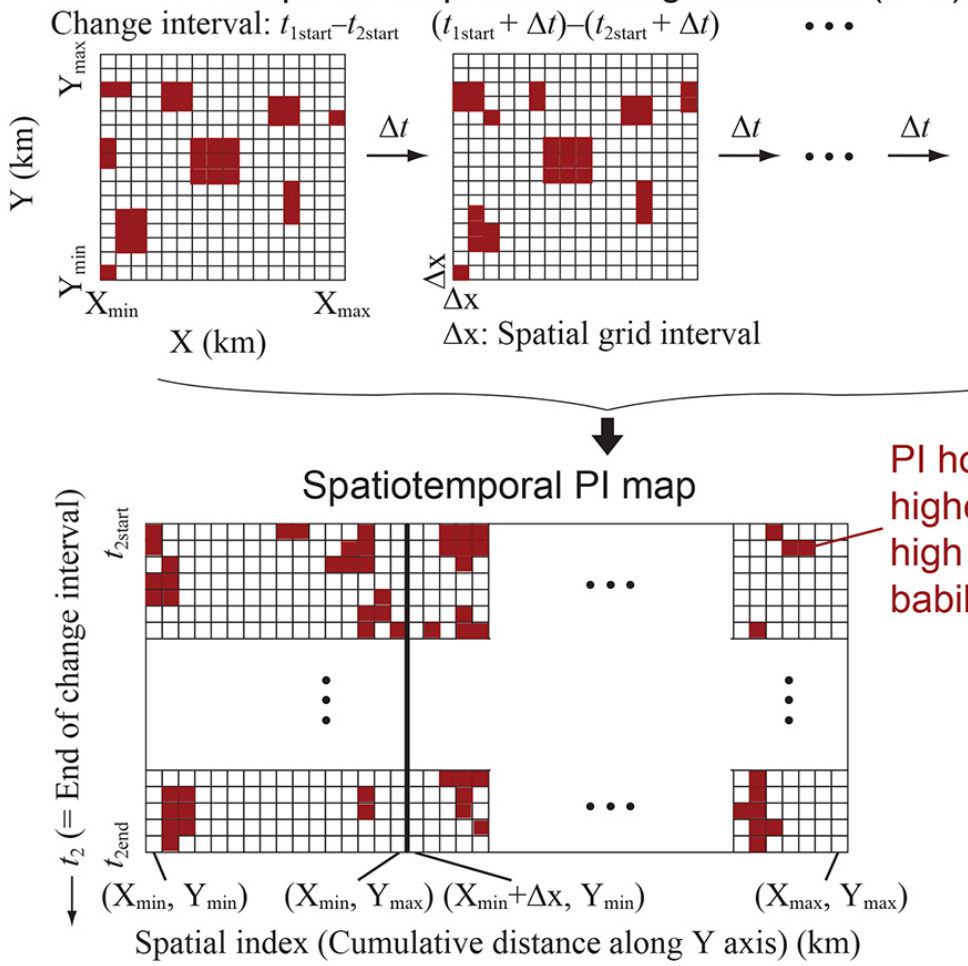

Fig. 2. (a) Flowchart of the procedure for obtaining PI maps, which illustrate the spatial distribution of grid cells with large seismicity changes above a particular threshold (referred to as PI hotspots). (b) Illustration of the method for obtaining the spatiotemporal PI map obtained by combining PI maps obtained based on the process described in (a). The $X$ and $Y$ axes in each PI map correspond to those of the rectangular region in each panel of Fig. 1. The thick vertical black line in the spatiotemporal PI map represents the edges of the $Y$ axis range. 
Table 1. Earthquake index assigned to each of 12 large earthquakes with magnitudes larger than $M=6.4$ with corresponding occurrence date, epicenter (longitude and latitude), depth, and magnitude.

\begin{tabular}{llrrrr}
\hline $\begin{array}{l}\text { Earthquake } \\
\text { index }\end{array}$ & Date & Longitude $\left(^{\circ}\right)$ & Latitude $\left(^{\circ}\right)$ & $\begin{array}{r}\text { Depth } \\
(\mathrm{km})\end{array}$ & Magnitude \\
\hline (A) & 1 Jul. 2000 & 139.19 & 34.19 & 16.1 & 6.5 \\
$(\mathrm{~B})$ & 30 Jul. 2000 & 139.41 & 33.97 & 17.0 & 6.5 \\
$(\mathrm{C})$ & 6 Oct. 2000 & 133.35 & 35.27 & 9.0 & 7.3 \\
$(\mathrm{D})$ & 26 Jul. 2003 & 141.17 & 38.41 & 11.9 & 6.4 \\
$(\mathrm{E})$ & 23 Oct. 2004 & 138.87 & 37.29 & 13.1 & 6.8 \\
$(\mathrm{~F})$ & 23 Oct. 2004 & 138.93 & 37.31 & 14.2 & 6.5 \\
$(\mathrm{G})$ & 20 Mar. 2005 & 130.18 & 33.74 & 9.2 & 7.0 \\
$(\mathrm{H})$ & 25 Mar. 2007 & 136.69 & 37.22 & 10.7 & 6.9 \\
$(\mathrm{I})$ & 16 Jul. 2007 & 138.61 & 37.56 & 16.8 & 6.8 \\
$(\mathrm{~J})$ & 14 Jun. 2008 & 140.88 & 39.03 & 7.8 & 7.2 \\
$(\mathrm{~K})$ & 20 Dec. 2008 & 142.70 & 36.53 & 0.0 & 6.6 \\
$(\mathrm{~L})$ & 11 Aug. 2009 & 138.50 & 34.79 & 23.3 & 6.5 \\
\hline
\end{tabular}

values lower than -0.4 and highlight locations with only small changes in seismic activity, indicating low earthquake occurrence probability in the prediction period. The red and white stars in each panel represent the spatiotemporal locations of target (i.e., $M \geq 6.4$ ) earthquakes (Table 1). In particular, the red stars indicate target earthquakes that occurred in the prediction periods following change intervals with the common logarithm of PI values higher than -0.4 , whereas the white stars indicate that the target earthquakes occurred outside the prediction periods. For convenience, we hereafter refer to the total spatiotemporal area occupied by prediction periods that follow change intervals with large seismicity changes (or high earthquake occurrence probabilities) as the alarm area.

Figures 6-9 show the spatiotemporal alarm area maps for the same cutoff magnitudes as in Figs. 3-5, respectively; panels a-f in Figs. 6-9 denote the alarm area maps for different change intervals of $4,6,8,10,12$, and 14 years, respectively. White grid cells illustrate the alarm area. Black grid cells show the nonalarm area, which indicates the total spatiotemporal areas outside the alarm area. The black and white stars correspond to the red and white stars in Figs. 3-5, respectively; labels A-L in panels a and d denote the earthquake indices in Table 1.

Here, we focus on whether each large earthquake occurred within the alarm area. Therefore, it is necessary to quantitatively compare the statistical performance of the spatiotemporal PI maps for different cutoff magnitudes, different change intervals, and different lower thresholds of PI value representing large seismicity change during the change interval or high earthquake occurrence probability during the prediction period. For this purpose, we used Molchan's error diagram (Kagan, 2007; Molchan, 1997; Shcherbakov et al., 2010) to examine the coherence between the spatiotemporal locations of target earthquakes and the fraction of grid cells occupied by the alarm area. Figures 9-11 present plots of miss rate versus fraction of grid cells occupied by the alarm area. Here, miss rate is defined as the number of $M \geq 6.4$ events located outside the alarm area normalized by the total number of $M \geq 6.4$ events. A line connecting $(0,1)$ to $(1,0)$ indicates the random miss rate, which corresponds to a line of no significance. We used the method of Zechar and Jordan (2008) to calculate the lower $95 \%$ confidence level of the random miss rate. In the statistical test, variation in the miss rate in response to changes in the alarm area was calculated by changing the lower threshold of PI values that correspond to large seismicity changes (black open circles in Figs. 911). The best performance of the PI method is found in the bottom-left corner of each diagram. Conversely, we do not regard the performance in areas of the plot above and to the right of the lower $95 \%$ confidence level curve of the random miss rate as statistically significant. Therefore, we focused primarily on the data represented by the black open and large black solid circles located below and to the left of the lower $95 \%$ confidence level curve. The large black solid circles in Figs. 9-11 correspond to the results shown in Figs. 3-8, which were obtained by setting the lower threshold of the common logarithm of the PI value representing large seismicity change during the change interval to -0.4 .

Statistical features of Molchan's error diagrams for respective cutoff magnitudes (Figs. 9-11) can be described as follows. As to cutoff magnitude of 3.5, miss rates and fractions of grid cells occupied by alarm areas (denoted by black open circles and large black solid circles in Fig. 9) for 8 or 10 year change intervals (Fig. 9c, d) performed better than those for other change intervals although they are located primarily above and to the right of the lower $95 \%$ confidence level curve. In the case of a cutoff magnitude of 4.0, miss rates and fractions of grid cells occupied by alarm areas for 8,10 , or 12 year change intervals (Fig. 10c-e) showed better performances than for other change intervals. Especially, the statistical performance for the 10 year change interval is 

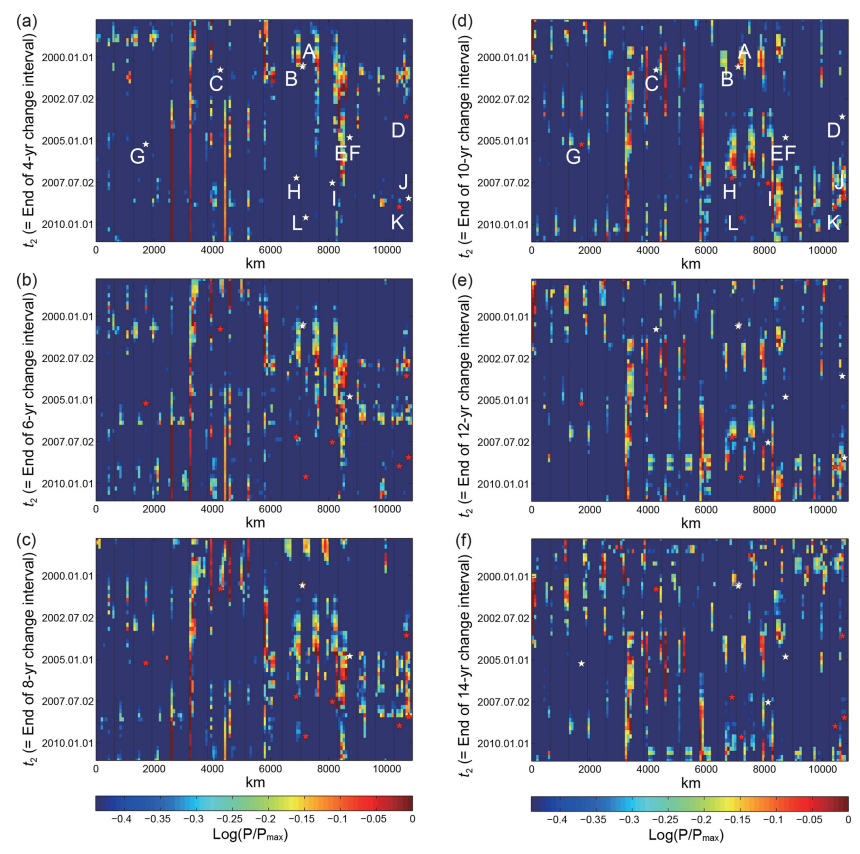

Fig. 3. Spatiotemporal PI maps for a cutoff magnitude of 3.5, illustrating the locations of grid cells with large seismicity changes (PI hotspots) for different change intervals between $t_{1}$ and $t_{2}\left(t_{2}-t_{1}=\right.$ $4,6,8,10,12$, and 14 years; $t_{2}=1$ January $1997-28$ February 2011). Length of change interval for each panel is shown on the labels of vertical axes. $\log \left(P / P_{\max }\right)$ means the common logarithm of the PI value (Fig. 2a). Grid cells with the common logarithm of PI values greater than -0.4 (i.e., between -0.4 and 0 ) are regarded as locations with large seismicity changes, including seismic quiescence and activation, during the specified change interval. Red grid cells correspond to the highest probability of earthquake occurrence. Deep blue cells indicate values lower than -0.4 , representing locations with small seismicity changes and indicating low probabilities of earthquake occurrences in the prediction periods following the change intervals. Horizontal and vertical axes denote the cumulative distance along the $Y$ axis and the end of change interval used for evaluating seismicity change, respectively (Figs. 1, 2b). The red stars indicate the locations of target earthquakes that occurred in the prediction periods following the change intervals with large seismicity changes. The white stars denote those with small seismicity changes. The vertical black lines, which correspond to those in the spatiotemporal PI map as shown in Fig. 2, represent the north-northwest and south-southeast edges of the Y axis of the rectangular analysis region as shown in Fig. 1. The labels (A)-(L) correspond to the earthquake indices in Table 1.

statistically significant in that the black open and large black solid circles are located primarily below and to the left of the lower $95 \%$ confidence level curve of the random miss rate. For the cutoff magnitude of 4.5, miss rates and fractions of grid cells occupied by alarm areas (shown in Fig. 11c and d) were plotted primarily below and to the left of the lower $95 \%$ confidence level curve of the random miss rate when 8 or 10 year change intervals were adopted, indicating that the
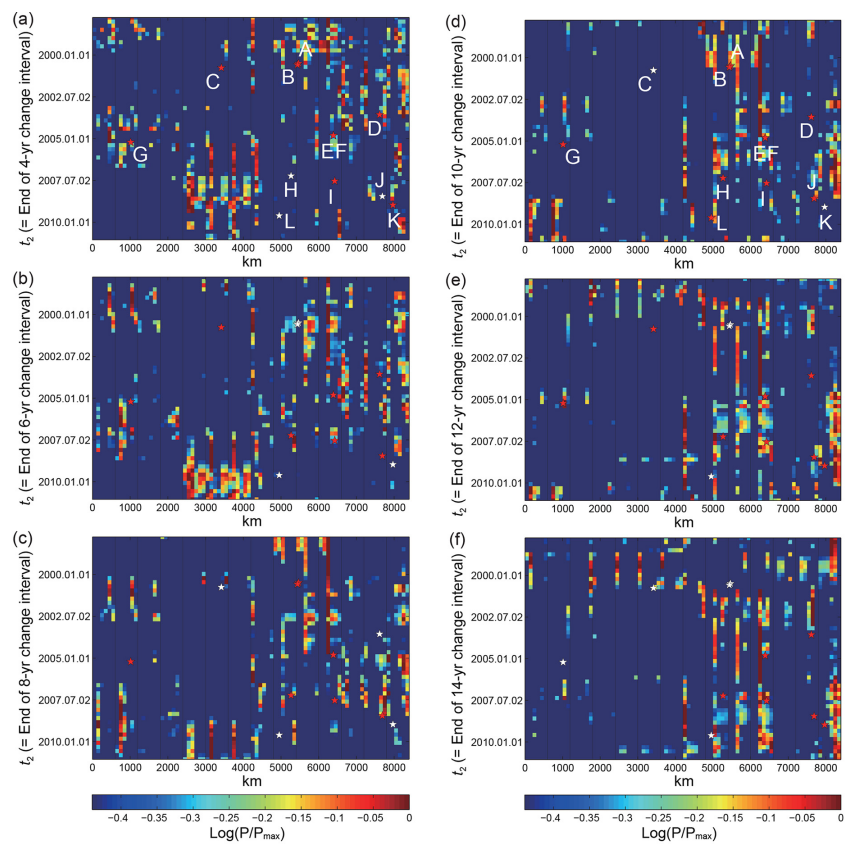

Fig. 4. As in Fig. 3, but for a cutoff magnitude of 4.0.
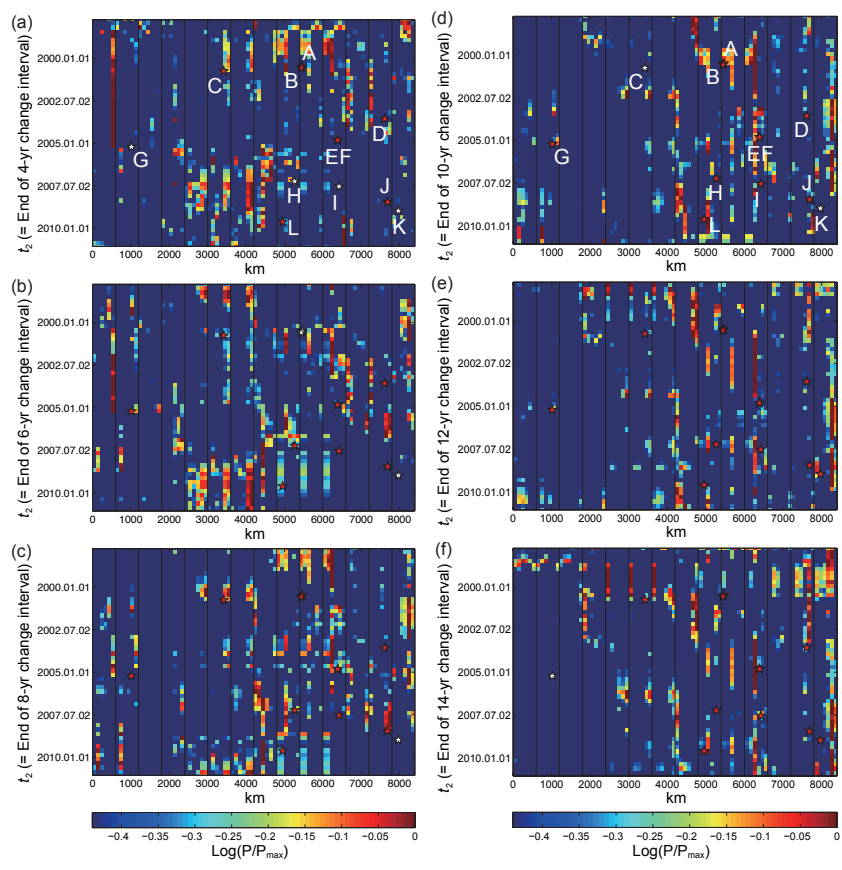

Fig. 5. As in Fig. 3, but for a cutoff magnitude of 4.5.

PI method performed better for 8 or 10 year change intervals than for others.

Summarizing the common statistical performance of the error diagrams for cutoff magnitudes of $3.5,4.0$, and 4.5 (Figs. 9-11), there appears to be some relationship between the locations of $M \geq 6.4$ events and the number of grid cells occupied by alarm areas for 8 or 10 year change intervals. 

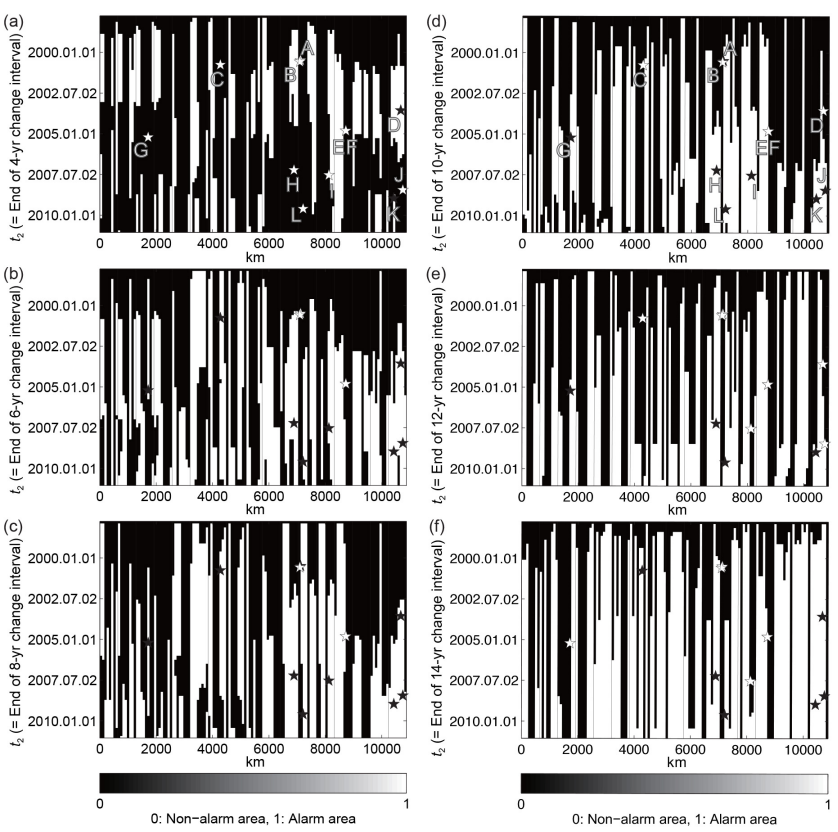

Fig. 6. Spatiotemporal distribution of the alarm area for a cutoff magnitude of 3.5. The alarm area is defined as the total spatiotemporal area occupied by the prediction periods that follow the change intervals with large seismicity changes, or with the common logarithm of PI values higher than -0.4 . The black and white stars correspond to the red and white stars in Figs. 3-5, respectively. White grid cells correspond to the alarm area; black grid cells show the nonalarm area, which is defined as the complement of the alarm area. The vertical black lines and horizontal and vertical axes are as in Fig. 3. The labels (A)-(L) correspond to the earthquake indices in Table 1.
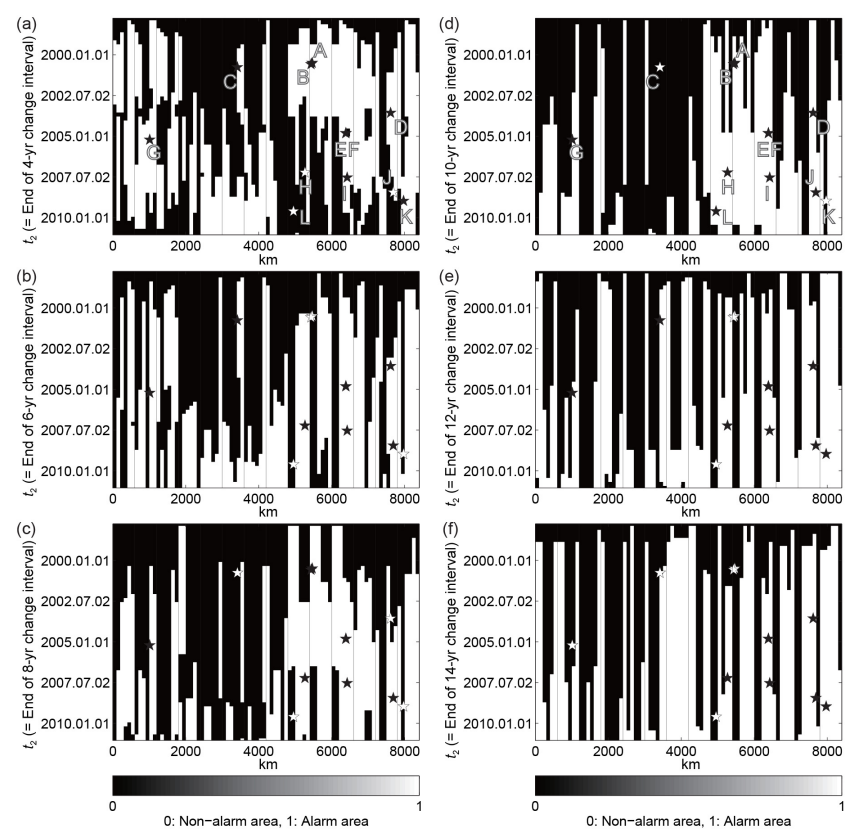

Fig. 7. As in Fig. 6, but for a cutoff magnitude of 4.0.
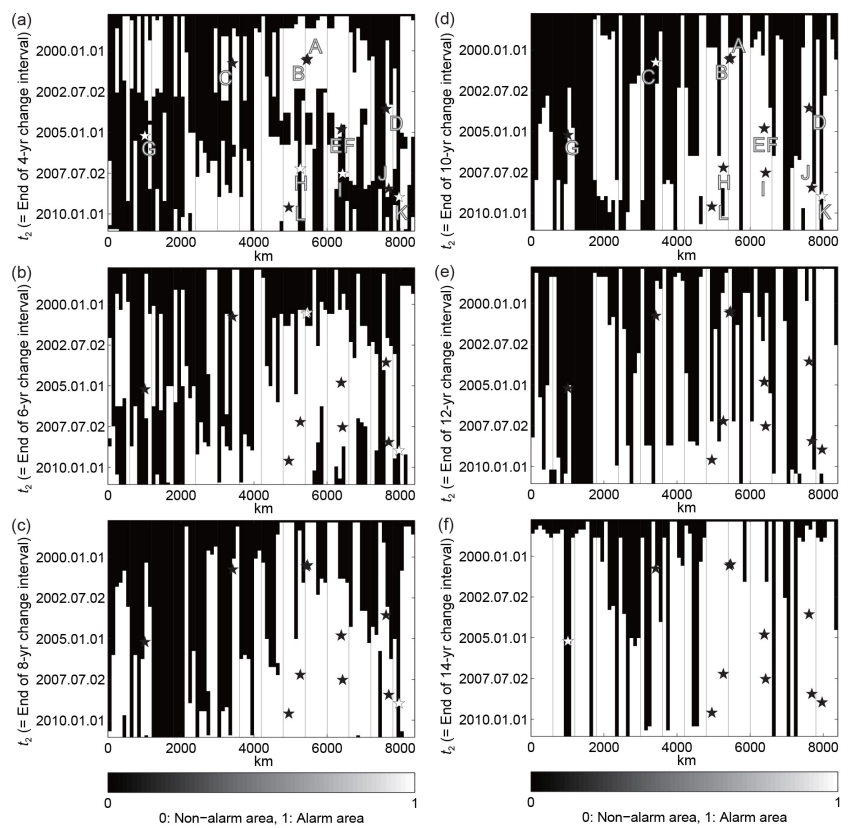

Fig. 8. As in Fig. 6, but for a cutoff magnitude of 4.5 .

Especially, for cutoff magnitudes of 4.0 (10 year change intervals) and 4.5 ( 8 or 10 year change intervals), the null hypothesis, which states that there is no significant relationship between the locations of $M \geq 6.4$ events and the number of grid cells occupied by alarm areas, was rejected at a confidence level of $95 \%$. In addition to showing that application of the PI method to the shallow earthquake data of Japan produces the best statistical results for change intervals of 8 10 years, this statistical performance demonstrates that such change intervals reflect the characteristic time period associated with preparation for the occurrence of large shallow earthquakes in Japan.

\section{Discussion and conclusions}

We applied the PI method to the earthquake catalog covering the inland areas of Japan. Because seismicity rate is a proxy for stress rate (Dieterich, 1994; Dieterich et al., 2000; Toda et al., 2002), the position of a PI hotspot is considered to reflect an area with significant temporal change in stress rate during a given change interval. In the present study, we focused on the occurrence (or nonoccurrence) of each large shallow earthquake that occurred during each prediction period, where the prediction period followed a change interval in which the observed seismicity change exceeded a given threshold; we varied the threshold as part of a statistical test using Molchan's diagram to check the robustness of the analysis result and to infer the characteristic timescale of precursory anomalous seismic activity. Typically, in cases where PI hotspots are located on the epicenter of a large 

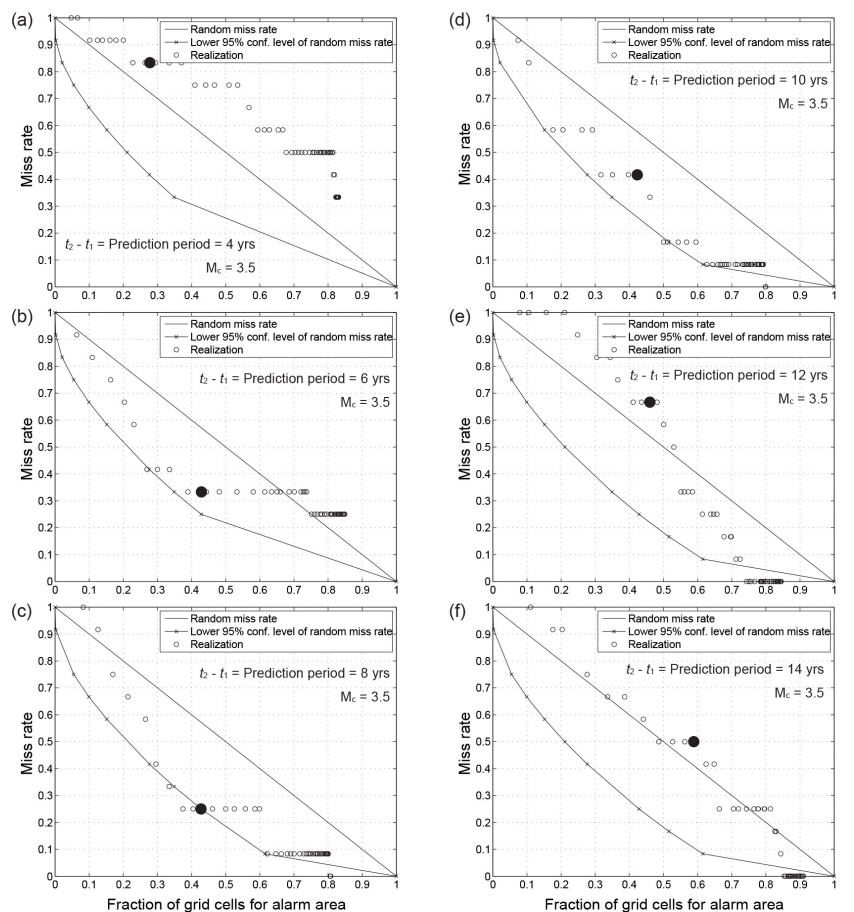

Fig. 9. Molchan's error diagrams for different change intervals between $t_{1}$ and $t_{2}\left(t_{2}-t_{1}=4,6,8,10,12\right.$, and 14 years; $t_{2}=1$ January 1997-28 February 2011). Vertical axis denotes the miss rate, which is defined as the number of $M \geq 6.4$ earthquakes occurred outside the alarm area relative to the total number of $M \geq 6.4$ earthquakes. Horizontal axis shows fraction of all grid cells occupied by prediction periods following change intervals with the common logarithm of PI values greater than -0.4 . A line connecting $(0,1)$ to $(1,0)$ indicates the random miss rate, which shows no statistical significance. A curve with crosses is the lower $95 \%$ confidence level of the random miss rate, which was calculated using the method of Zechar and Jordan (2008). The performance in areas of the plot above and to the right of the curve is not regarded as statistically significant. Open circles were calculated by changing the lower threshold of the common logarithm of PI values above which (toward zero) temporal change in seismic activity is large; the large solid circle is calculated by setting the lower threshold to -0.4 .

inland earthquake, the stress rate around the focal region of the earthquake increases. Therefore, the observation of temporal change in the locations of PI hotspots is a key factor in improving the physical understanding of stress state near the source area of a future, large inland earthquake and the preparatory processes of such earthquakes. As discussed in Sect. 3, our analysis identified PI hotspots on a timescale of 8-10 years in regions within the focal regions of all target earthquakes prior to their occurrences.

Some previous studies have examined such precursory seismicity changes related to large inland earthquakes in Japan. Takahashi and Kumamoto (2006) discussed the relationships between some seismic indices and the degree of fault evolution by investigating temporal changes in the
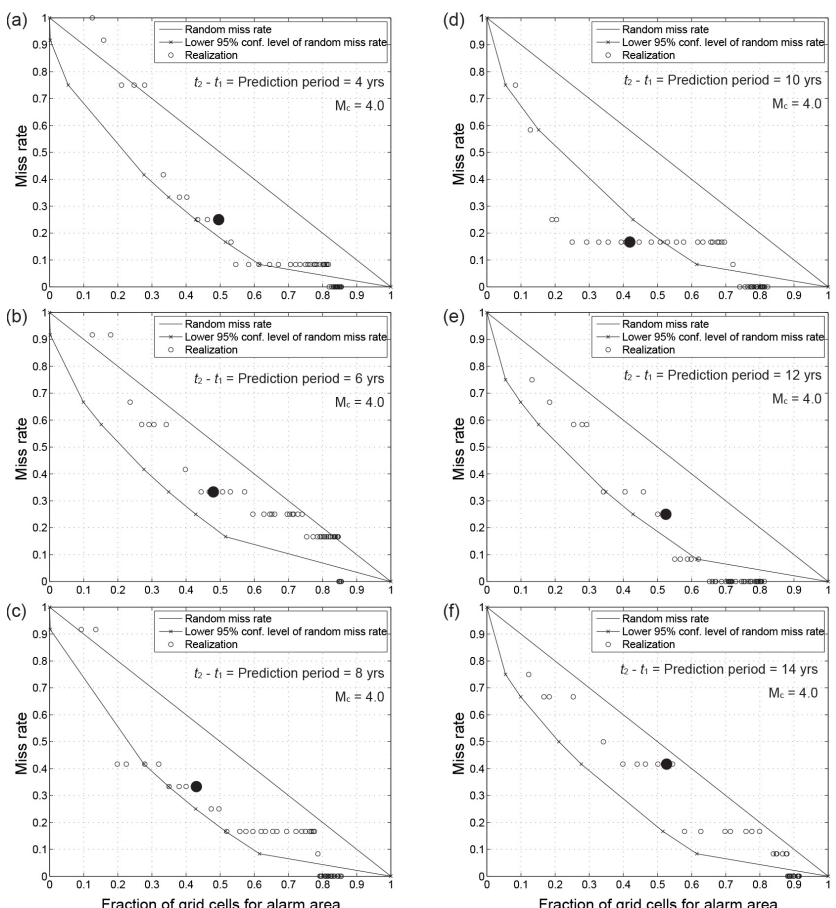

Fig. 10. As in Fig. 9, but for a cutoff magnitude of 4.0.
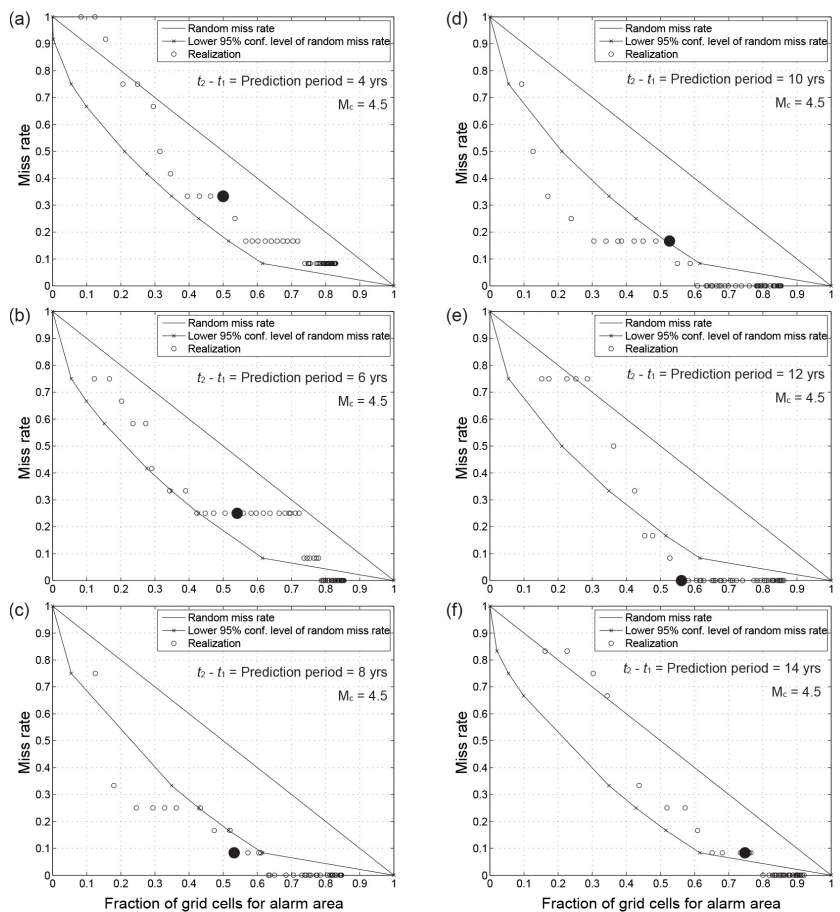

Fig. 11. As in Fig. 9, but for a cutoff magnitude of 4.5.

seismic indices prior to the occurrences of eight large inland earthquakes in Japan; in fact, four of these earthquakes were also included in the present study (earthquake indices (C), (D), (E), and (G) in Table 1). The seismic indices used 
included the cumulative number of earthquakes, the $a$ and $b$ values of the Gutenberg-Richter relation (Gutenberg and Richter, 1944), the AS function (Habermann, 1983), and the LTA (long-term average) function (Habermann, 1991; Wu and Chiao, 2006). The results presented by Takahashi and Kumamoto (2006) demonstrated that precursory seismic quiescence occurred on timescales of 1-7 years over areas at spatial scales of $\sim 100 \mathrm{~km}$, centered at the epicenters of large inland earthquakes (C), (D), (E), and (G) in Table 1. Although it appears that the precursory time intervals determined by Takahashi and Kumamoto (2006) are inconsistent with those obtained in the present study, this may be due to differences in the areas included when calculating the temporal changes in seismic activity: the areas of $240 \mathrm{~km} \times 240 \mathrm{~km}$ and $300 \mathrm{~km} \times 300 \mathrm{~km}$ used in the present study are more extensive than the areas of $0.2^{\circ} \times 0.2^{\circ}$ and $1^{\circ} \times 1^{\circ}$ used by Takahashi and Kumamoto (2006).

Yoshida and Aoki (2002) examined the seismic activity that occurred prior to the 1891 Nobi earthquake (Mikumo and Ando, 1976; Nakano et al., 2007), the 1964 Niigata earthquake (Hirasawa, 1965), the 1983 central Japan Sea earthquake (Satake, 1985), and the 2000 western Tottori Prefecture earthquake in Japan (earthquake index (C) in Table 1; Fukuyama et al., 2003; Ohmi et al., 2002). Their results indicated that the precursory seismic quiescence of the earthquakes occurred more than 10 years before the earthquakes. Moreover, the results for the 2000 western Tottori Prefecture earthquake indicated that the related precursory seismic quiescence began to occur 10 years before the occurrence of the earthquake within a rectangular region of $150 \mathrm{~km} \times 350 \mathrm{~km}$ that included the earthquake's source area. It should be noted that the earthquake occurrence probabilities obtained in the present study were obtained for square regions measuring $240 \mathrm{~km} \times 240 \mathrm{~km}$ and $300 \mathrm{~km} \times 300 \mathrm{~km}$, centered at the respective calculation grids; this is very similar to the scale of Yoshida and Aoki (2002). Therefore, the precursory time interval (for timescales of 8-10 years) obtained in the present study seems to be consistent with that obtained by Yoshida and Aoki (2002).

The PI method can identify locations of anomalous seismic activity including both seismic quiescence and activation. Therefore, it is able to highlight areas of stress relaxation and stress concentration in and around the source areas of future, large earthquakes. According to Yoshida and Aoki (2002), seismic quiescence occurred over a broader region around the source area of the 2000 western Tottori Prefecture earthquake; meanwhile, seismicity remained active in the source area. Yoshida and Aoki (2002) interpreted this observation to be a result of the transfer of stress into asperities within the source area, possibly due to stress relaxation processes in the surrounding region. Wyss et al. (1981) and Wyss (1986) reached similar conclusions in the cases of the 1975 Kalapana, Hawaii, earthquake and the 1983 Kaoiki, Hawaii, earthquake, respectively. Furthermore, based on a numerical simulation using rate- and state-dependent friction laws $(\mathrm{Ru}-$ ina, 1983), Kato et al. (1997) demonstrated the appearance of regional seismic quiescence in the continental crust before a large interplate earthquake due to regional stress relaxation; such relaxation could occur as a result of preseismic sliding on the boundary between a subducting oceanic plate and the overriding continental plate. Kato et al. (1997) also argued that the mechanism underlying seismic quiescence could apply to other types of earthquakes, including intraplate earthquakes on active faults. Therefore, the anomalous seismicity obtained in the present study may reflect a temporal change in crustal seismicity associated with regional stress relaxation prior to a large earthquake (Kawamura et al., 2013; Wu and Chiao, 2006; Wu et al., 2008a, b).

We conclude that anomalous seismic activity likely precedes the occurrence of $M=6$ or $M=7$ large shallow earthquakes in inland areas of Japan on timescales of 8-10 years. In considering the implications of our study for the preparatory processes of large shallow earthquakes in Japan, it would be informative to investigate the existence of anomalous seismic activity preceding large earthquakes elsewhere. Moreover, if such activity were found, it would be enlightening to compare the associated timescales with those described for Japan in the present study. This should provide a more comprehensive understanding of the mechanisms responsible for the occurrence of large shallow earthquakes.

Acknowledgements. We thank the Japan Meteorological Agency (JMA) for the use of the unified earthquake catalog. Each hypocenter in the catalog was determined by analyzing, in an integrated fashion, the earthquake data of Hokkaido University, Hirosaki University, Tohoku University, the University of Tokyo, Nagoya University, Kyoto University, Kochi University, Kyushu University, Kagoshima University, the National Research Institute for Earth Science and Disaster Prevention (NIED), the National Institute of Advanced Industrial Science and Technology (AIST), the Japan Agency for Marine-Earth Science and Technology (JAMSTEC), the Tokyo Metropolitan Government, Yokohama City, Shizuoka Prefecture, the Hot Springs Research Institute of Kanagawa Prefecture, and the JMA. Data can be obtained from the Japan Meteorological Business Support Center. This research was supported financially by the National Science Council (ROC).

Edited by: B. D Malamud

Reviewed by: R. Console and one anonymous referee

\section{References}

Borovik, N., Misharina, L., and Treskov, A.: On the possibility of strong earthquakes in Pribakalia in the future, Izv. Acad. Sci. USSR Phys. Solid Earth, English Transl., 1, 13-16, 1971.

Bowman, D. D. and King, G. C. P.: Accelerating seismicity and stress accumulation before large earthquakes, Geophys. Res. Lett., 28, 4039-4042, 2001.

Bowman, D. D., Ouillon, G., Sammis, G., Sornette, A., and Sornette, D.: An observed test of the critical earthquake concept, J. Geophys. Res., 103, 24359-24372, 1998. 
Bufe, C. G. and Varnes, D. J.: Predictive modeling of the seismic cycle of the greater San Francisco Bay region, J. Geophys. Res., 98, 9871-9883, 1993.

Bufe, C. G., Nishenko, S. P., and Varnes, D. J.: Seismicity trends and potential for large earthquakes in the Alaska-Aleutian region, Pure Appl. Geophys., 142, 83-99, 1994.

Chen, C. C.: Accelerating seismicity of moderate-size earthquakes before the 1999 Chi-Chi, Taiwan, earthquake: Testing timeprediction of the self-organizing spinodal model of earthquakes, Geophys. J. Int., 155, F1-F5, 2003.

Chen, C. C. and Wu, Y. X.: An improved region-time-length algorithm applied to the 1999 Chi-Chi, Taiwan earthquake, Geophys. J. Int., 166, 1144-1147, 2006.

Chen, C. C., Rundle, J. B., Holliday, J. R., Nanjo, K. Z., Turcotte, D. L., Li, S. C., and Tiampo, K. F.: The 1999 ChiChi, Taiwan, earthquake as a typical example of seismic activation and quiescence, Geophys. Res. Lett., 32 L22315, doi:10.1029/2005GL023991, 2005.

Chen, C. C., Rundle, J. B., Li, H. C., Holliday, J. R., Nanjo, K. Z., Turcotte, D. L., and Tiampo, K. F.: From tornadoes to earthquakes: Forecast verification for binary events applied to the 1999 Chi-Chi, Taiwan, earthquake, Terr. Atmos. Ocean. Sci., 17, 503-516, 2006.

Console, R., Montuori, C., and Murru, M.: Statistical assessment of seismicity patterns in Italy: Are they precursors of subsequent events?, J. Seismol., 4, 435-449, 2000.

Dieterich, J.: A constitutive law for rate of earthquake production and its application to earthquake clustering, J. Geophys. Res., 99, 2601-2618, doi:10.1029/93JB02581, 1994.

Dieterich, J., Cayol, V., and Okubo, P.: The use of earthquake rate changes as a stress meter at Kilauea volcano, Nature, 408, 457460, 2000.

Gutenberg, B. and Richter, D. F.: Frequency of earthquakes in California, B. Seismol. Soc. Am., 34, 185-188, 1944.

Habermann, R. E.: Teleseismic detection in the Aleutian island arc, J. Geophys. Res., 88, 5056-5064, 1983.

Habermann, R. E.: Man-made changes of seismicity rates, B. Seismol. Soc. Am., 77, 141-159, 1987.

Habermann, R. E.: Seismicity rate variations and systematic changes in magnitudes in teleseismic catalogs, Tectonophysics, 193, 277-289, 1991.

Hirasawa, T.: Source mechanism of the Niigata Earthquake of June 16, 1964, as derived from body waves, J. Phys. Earth, 13, 35-66, 1965.

Holliday, J. R., Nanjo, K. Z., Tiampo, K. F., Rundle, J. B., Turcotte, D. L., and Donnellan, A.: Forecasting the locations of future earthquake and its verification, Nonlinear Proc. Geoph., 12, 965-977, 2005.

Holliday, J. R., Rundle, J. B., Tiampo, K. F., Klein, W., and Donnellan, A.: Systematic procedural and sensitivity analysis of the pattern informatics method for forecasting large $(M>5)$ earthquake events in southern California, Pure Appl. Geophys., 163, 2433-2454, 2006.

Huang, Q., Sobolev, G. A., and Nagao, T.: Characteristics of the seismic quiescence and activation patterns before the $M=7.2$ Kobe earthquake, January 17, 1995, Tectonophysics, 337, 99116, 2001
Imanishi, K., Kuwahara, Y., and Haryu, Y.: Off-fault aftershocks of the 2005 West Off Fukuoka Prefecture Earthquake: Reactivation of a structural boundary?, Earth Planets Space, 58, 81-86, 2006.

Jaume S. C. and Sykes, L. R.: Evolving towards a circular point: A review of accelerating seismic moment/energy release prior to large and great earthquakes, Pure Appl. Geophys., 155, 279-306, 1999.

Kagan, Y. Y.: On earthquake predictability measurement: information score and error diagram, Pure Appl. Geophys., 164, 19471962, 2007.

Karakaisis, G. F, Papazachos, C. B., Savvaidis, A. S., and Papazachos, B. C.: Accelerating seismic crustal deformation in the North Aegean Trough, Greece, Geophys. J. Int., 148, 193-200, 2002.

Kato, N., Ohtake, M., and Hirasawa, T.: Possible mechanism of precursory seismic quiescence: regional stress relaxation due to preseismic sliding, Pure Appl. Geophys., 150, 249-267, 1997.

Katsumata, K.: A long-term seismic quiescence started 23 years before the 2011 off the Pacific coast of Tohoku Earthquake $(M=9.0)$, Earth Planets Space, 63, 709-712, 2011a.

Katsumata, K.: Precursory seismic quiescence before the $M_{\mathrm{W}}=8.3$ Tokachi-oki, Japan, earthquake on 26 September 2003 revealed by a re-examined earthquake catalog, J. Geophys. Res., 116, B10307, doi:10.1029/2010JB007964, 2011b.

Kawamura, M., Wu, Y. H., Kudo, T., and Chen, C. C.: Precursory migration of anomalous seismic activity revealed by the pattern informatics method: A case study of the 2011 Tohoku earthquake, Japan, B. Seismol. Soc. Am., 1171-1180, 2013.

Kisslinger, K. and Kindel, B.: A comparison of seismicity rates near Adak Island, Alaska, September 1988 through May 1990 with rates before the 1982 to 1986 apparent quiescence, B. Seismol. Soc. Am., 84, 1560-1570, 1994.

Ma, K.-F., Chan, C.-H., and Stein, R. S.: Response of seismicity to Coulomb stress triggers and shadows of the $1999 M_{\mathrm{W}}=7.6$ Chi-Chi, Taiwan, earthquake, J. Geophys. Res., 110, B05S19, doi:10.1029/2004JB003389, 2005.

Mikumo, T. and Ando, M.: A search into the faulting mechanism of the 1891 great Nobi earthquake, J. Phys. Earth., 24, 63-87, 1976.

Mogi, K.: Some features of recent seismic activity in and near Japan (2), B. Earthq. Res. Inst. Tokyo, 46, 30-36, 1969.

Nagao, T., Takeuchi, A., and Nakamura, K.: A new algorithm for the detection of seismic quiescence: introduction of the RTM algorithm, a modified RTL algorithm, Earth Planets Space, 63, 315-324, 2011.

Nakano, M., Miyakoshi, J., and Yamaoka, K.: A new model for the fault beneath the sedimentary basin in the 1891 Nobi earthquake, Earth Planets Space, 59, 13-19, 2007.

Ogata, Y.: Seismicity quiescence and activation in western Japan associated with the 1944 and 1946 great earthquakes near the Nankai trough, J. Geophys. Res., 109, B04305, doi:10.1029/2003JB002634, 2004.

Ogata, Y.: Detection of anomalous seismicity as a stress change sensor, J. Geophys. Res., 110, B05S06, doi:10.1029/2004JB003245, 2005.

Öztürk, S. and Bayrak, Y.: Spatial variations of precursory seismic quiescence observed in recent years in the eastern part of Turkey, Acta Geophys., 60, 92-118, 2012. 
Papazachos, C. B., Karakaisis, G. F., Scordilis, E. M., and Papazachos, B. C.: Global observational properties of the critical earthquake model, B. Seismol. Soc. Am., 95, 1841-1855, 2005.

Papazachos, B. C., Karakaisis, G. F., Scordilis, E. M., Papazachos, C. B., and Panagiotopoulos, D. G.: Present patterns of decelerating-accelerating seismic strain in South Japan, J. Seismol., 14, doi:10.1007/s10950-009-9165-z, 2010.

Resenberg, P. A. and Matthews, M. V.: Precursory seismic quiescence: a preliminary assessment of the hypothesis, Pure Appl. Geophys., 126, 373-406, 1988.

Ruina, A. L.: Slip instability and state variable friction laws, J. Geophys. Res., 88, 10359-10370, 1983.

Rundle, J. B., Klein, W., Tiampo, K., and Gross, S.: Linear pattern dynamics in nonlinear threshold systems, Phys. Rev. E, 61, 2418-2431, 2000.

Rundle, J. B., Tiampo, K. F., Klein, W., and Martins, J. S. Sá: Selforganization in leaky threshold systems: The influence of nearmean field dynamics and its implications for earthquakes, neurobiology, and forecasting, P. Natl. Acad. Sci. USA, 99, suppl., 2514-2521, 2002.

Rundle, J. B., Turcotte, D. L., Shcherbakov, R., Klein, W., and Sammis, C.: Statistical physics approach to understanding the multiscale dynamics of earthquake fault systems, Rev. Geophys., 41, 1019, doi:10.1029/2003RG000135, 2003.

Satake, K.: The mechanism of the 1983 Japan Sea earthquake as inferred from long-period surface waves and tsunamis, Phys. Earth Planet. In., 37, 249-260, 1985.

Shcherbakov, R., Turcotte, D. L., Rundle, J. B., Tiampo, K. F., and Holliday, J. R.: Forecasting the locations of future large earthquakes: an analysis and verification, Pure Appl. Geophys., 167, 743-749, 2010.

Sobolev, G. A.: Application of the RTL algorithm to the analysis of preseismic processes before strong earthquakes in California, Äul Izvestiya-Physics of the Solid Earth, 39, 179-188, 2003.

Stein, R. S.: The role of stress transfer in earthquake occurrence, Nature, 402, 605-609, 1999.

Stuart, W. D.: Seismic quiescence at Parkfield due to detachment faulting, Nature, 349, 58-61, 1991.

Sykes, L. R. and Jaume, S. C.: Seismic activity on neighboring faults as a long-term precursor to large earthquakes in the San Francisco Bay area, Nature, 348, 595-599, 1990.

Takahashi, N. and Kumamoto, T.: Preliminary investigation of seismicity rate change immediately before mainshock and fault maturity for damaging intraplate earthquakes in Japan, Active Fault Research, 26, 15-28, 2006 (in Japanese with English abstract).
Tiampo, K. F., Rundle, J. B., McGinnis, S., Gross, S. J., and Klein, W.: Mean-field threshold systems and phase dynamics: An application to earthquake fault systems, Europhys. Lett., 60, 481-487, 2002.

Toda, S., Stein, R. S., and Sagiya, T.: Evidence from the AD 2000 Izu islands earthquake swarm that stressing rate governs seismicity, Nature, 419, 58-61, 2002.

Wei, G., Lin, Z., Zhu, X., Zhao, Y., Zhao, X., and Hou, H.: On seismic gaps previous to certain great earthquakes occurred in north China, Acta Geophys. Sin., 21, 213-217, 1978.

Wiemer, S. and Wyss, M.: Minimum magnitude of completeness in earthquake catalogs: Examples from Alaska, the western United States, and Japan, B. Seismol. Soc. Am., 90, 859-869, 2000.

Wu, Y. M. and Chen, C. C. Seismic reversal pattern for the 1999 Chi-Chi, Taiwan, $M_{\mathrm{W}} 7.6$ earthquake, Tectonophysics, 429, 125132, 2007.

Wu, Y. M. and Chiao, L. Y.: Seismic quiescence before the 1999 Chi-Chi, Taiwan, $M_{\mathrm{w}} 7.6$ earthquake, B. Seismol. Soc. Am., 96, 321-327, 2006.

Wu, Y. H., Chen, C. C., and Rundle, J. B.: Precursory seismic activation of the Pintung (Taiwan) offshore doublet earthquakes on 26 December 2006: A pattern informatics analysis, Terr. Atmos. Ocean. Sci., 19, 743-749, 2008 a.

Wu, Y. H., Chen, C. C., and Rundle, J. B.: Detecting precursory earthquake migration patterns using the pattern informatics method, Geophys. Res. Lett., 35, L19304, doi:10.1029/2008GL035215, 2008b.

Wu, Y. H., Chen, C. C., and Rundle, J. B.: Precursory small earthquake migration patterns, Terra Nova, 23, 369-374, 2011.

Wyss, M., Klein, F. W., and Johnston, A. C.: Precursors to the Kalapana $M=7.2$ Earthquake, J. Geophys. Res., 86, 3881-3900, 1981.

Wyss, M.: Seismic quiescence precursor to the 1983 Kaoiki $\left(M_{S}=\right.$ 6.6), Hawaii, Earthquake, B. Seismol. Soc. Am., 76, 785-800, 1986.

Yoshida, A. and Aoki, G.: Seismic quiescence in a large area along the coast of the Japan Sea before large earthquakes, J. Geogr., 111, 212-221, 2002 (in Japanese with English abstract and figure captions).

Yu, H. Z., Cheng, J., Zhang, X. T., Zhang, L. P., Liu, J., and Zhang, Y. X.: Multi-methods combined analysis of future earthquake potential, Pure Appl. Geophys., 168, 173-183, doi:10.1007/s00024-011-0408-x, 2011.

Zheng, B., Hamburger, M. W., and Popandopulo, G. A.: Precursory seismicity changes preceding moderate and large earthquakes in the Garm region, Central Asia, B. Seismol. Soc. Am., 85, 571$589,1995$. 